\title{
PROFICIENCY OF ATTACK IN VOLLEYBALL AND ITS RELATIONS WITH ANTHROPOMETRIC CHARACTERISTICS IN U-16 BOYS
}

\author{
Raini Stamm ${ }^{1}$, Meelis Stamm ${ }^{2}$, Mark Kristjan Pitk ${ }^{1}$ \\ ${ }^{1}$ School of Natural Sciences and Health, Tallinn University \\ ${ }^{2}$ Headquarters of Estonian Defence Forces
}

\begin{abstract}
Attack has a very significant role in volleyball. It can be considered one of the most essential elements for scoring points. To perform successful attacks, certain body build characteristics are needed, which would facilitate the training of attack competence.

The aim of the current study was to assess the performance of attack by boys of the U-16 age group considering their body build and to analyse the differences of attack in sets won and lost.

To achieve the aim of the study, we had to solve the following tasks.

1. To assess the boys' body build based on height and weight in 5SD body build classes.

2. To analyse the players' proficiency at attack depending on their body build.

3. To find the main differences in attack in sets won and lost.

The number of boys studied was 66, and they all belonged to the eight best U-16 age group teams at the Estonian volleyball championships of 2017.

The study showed that spikes were performed most sucessfully by boys belonging to the big and leptomorph classes. The comparison of sets won and lost revealed that statistically significant differences were not caused by the number of points won at attack but by the number of failed spikes. In the sets won, the boys made statistically significantly fewer errors at spike.
\end{abstract}

Keywords: volleyball; adolescent; anthropometry; proficiency 


\section{INTRODUCTION}

Different anthropometric body types are suited for different sports [2]. Volleyball is a sport where morphological qualities greatly influence the results. Height is a great advantage in volleyball [9]. Research has shown that liberos have the smallest height and weight, while diagonal hitters have the largest height and weight [5]. High body mass, however, is an obstacle to achieving a good height of jump in volleyball [1]. Anthropometric dimensions play a very essential role in achieving success. It has been proved that anthropometric features show elite volleyball players' physical suitability to a certain position on the court. The results of a study by Nagendra have shown that there is a notable correlation between the volleyball players' physical suitability (anthropometry) and performance [6].

The Centre for Physical Anthropology at the University of Tartu has established new normative height and weight measurements for all age groups of Estonian schoolchildren from 7 to 18 years and normative values of belonging to 5SD classes [4]. This body build classification method, the 5SD height-weight classification, can also be successfully used for assessment of athletes [7], as it enables to assess the whole body size. BMI, which is widely used in sports, is mainly directed at the assessment of obesity, while the athletic qualities of the body, its size and height remain in the background. From the viewpoint of proficiency of attack in volleyball, however, these body build indicators are the most significant.

It is noteworthy that C. Raschka, in his textbook Sportanthropologie, called the five-class anthropometric SD classification created by Tartu anthropologists an innovative sport anthropological classification as early as in 2006 [7].

\section{MATERIAL AND METHODS}

The subjects of the study were young men of the U-16 age group who competed at Estonian championships at Kiili in spring 2017. The participants in the competition were the eight best young men's teams at the moment. In total, 66 boys participated in the study. During the whole tournament, 28 games were played in total - each team played 7 games.

During anthropometric research, 11 measurements were taken from each subject. The measurements included: height (with the precision of $0.5 \mathrm{~cm}$ ), height (with the precision of $0.1 \mathrm{~kg}$ ), fat percentage, height of the suprasternal notch, waist circumference, wrist circumference, lower leg circumference, and hand grip with dynamometer. Height was measured with an anthropometer. 
Circumferences were measured with a metal measuring tape. Fat percentage was computed with Tanita body composition monitor; weight was measured with the same device, and BMI and Rohrer index were calculated.

Proficiency of attack in volleyball was recorded with the program MaiaStats specially created for the Estonian Volleyball Federation. This program has been used in Estonian championship leagues since 2010 [10]. This program enables the statistician to record the activities of both teams. Actually, highly qualified experts recorded the performance of all the technical elements of the game, but in this paper, only attack is analysed. The recorder assessed the attack activities as follows:

BALL WON - A1, point from attack; the ball was hit to the ground, from the block to out of bounds, etc.

BALL REMAINING IN PLAY - A2, the attack remains in play (remains on the side of the opponent or is hit back from the block to one's own side).

ERROR AT ATTACK - A3, attack into the block; A4 - attack into the net, out of bounds, attacker in the net, attacker steps on the $3 \mathrm{~m}$ line.

ATTACK ERRORS TOTAL - A3+A4

For each player, the program calculated the number of points scored at attack, the number of points remaining in play, the number of points erred, the total number of points at attack by a player, and the percentage of the players' proficiency at attack. Later, additionally the mean indicators were calculated, proficiency of attack and proficiency index. The indicators of proficiency were calculated for the players who had performed at least five attacks during the tournament.

Proficiency $=$ Successful attacks - failed attacks / total number of attacks $\times 100$

Efficiency $=$ Successful attacks $/$ total number of attacks $\times 100$

Index of proficiency $=$ total number of performances $\times$ max grade sum of the grades $/($ max grade -1$) \times$ total number of performances

The data were analysed with the program SAS 8.2. Minimum and maximum values and standard deviations were calculated. For classification of anthropometric variables, we used the 5SD height and weight classification which is based on the boys' height and weight and their standard deviations. Based on their height and weight, the boys were grouped into five anthropometrically 
different classes: 1 . small class - small height, small weight; 2 . medium class medium height, medium weight; 3 . big class - big height, big weight. Additionally, two classes of discordant height and weight were created: pycnomorphs - small height and big weight, and leptomorphs - big height, small weight [3]. The boys' indicators of attack were placed into the five aforementioned classes according to their heights and weights. The results were compared statistically, and the level of statistical reliability was set at $\mathrm{p}<0.05$.

\section{RESULTS}

\section{Anthropometry}

The heights of the boys (aged 13-15 years) of all the eight teams who participated in the tournament varied from $157.5 \mathrm{~cm}$ to $195.5 \mathrm{~cm}$. The boys' mean height was $177.5 \mathrm{~cm}$ (SD 7.87) and the mean height of the suprasternal notch was $144.6 \mathrm{~cm}$ (SD 6.93). The boys' mean weight was $65.5 \mathrm{~kg}$ (SD 12.09). The mean fat percentage was $12.9 \%$ (SD 5.09), the mean body mass index 18.3 and Rohrer index 116.5. Three circumferences were taken from the boys - waist circumference, wrist circumference and lower leg circumference - and their mean values were respectively $73.9 \mathrm{~cm}$ (SD 6.46), $17 \mathrm{~cm}$ (SD 1.18) and $23.2 \mathrm{~cm}$ (SD 8.54) (see Table 1).

All the means were within the norm, and, individually, only one boy's body mass index was $>25$, which shows a tendency to obesity. We compared our results with Estonian school students' national norms [4] for each age group. This revealed that the mean height of Estonian 13-year-olds is $165.51 \mathrm{~cm}$, but in our volleyball players it was $176.81 \mathrm{~cm}$. The mean height of Estonian young men at the age of 14 is $169.62 \mathrm{~cm}$, in volleyball players $177.21 \mathrm{~cm}$, and in young men aged 15 the Estonian mean is $176.75 \mathrm{~cm}$, and the mean height of volleyball players of the same age was $181.91 \mathrm{~cm}$. The weight of volleyball players was also higher than the mean. The Estonian normative values as compared to the volleyball players were the following: 13 years $55.06-63.53 \mathrm{~kg}$; 14 years $58.59 \mathrm{~kg}-64.41 \mathrm{~kg} ; 15$ years $65.84 \mathrm{~kg}-70.65 \mathrm{~kg}$.

In addition to the anthropometric study, we also studied physical abilities by means of hand grip strength test measured by dynamometer. It is interesting to note that, when the means were compared, the boys' left hand grip was weaker than right hand grip. Most volleyball players were right-handed, and this explains the result. 
Table 1. Mean results of young men's anthropometric study and dynamometer test with maximums, minimums and standard deviations

\begin{tabular}{lcccc}
\hline $\mathrm{n}=66$ & $\begin{array}{c}\text { Mini- } \\
\text { mum }\end{array}$ & $\begin{array}{c}\text { Maxi- } \\
\text { mum }\end{array}$ & Mean & $\begin{array}{l}\text { Standard } \\
\text { deviation }\end{array}$ \\
\hline Age $(\mathrm{y})$ & 13 & 15 & 14.01515152 & 0.794063 \\
\hline Height $(\mathrm{cm})$ & 157.5 & 195.5 & 177.5151515 & 7.871062 \\
\hline Weight $(\mathrm{kg})$ & 42.6 & 102.3 & 65.53030303 & 12.09329 \\
\hline Fat mass \% & 4.1 & 25 & 12.91363636 & 5.092616 \\
\hline Body mass index & 12.8 & 28.3 & 18.39393939 & 2.903996 \\
\hline Rohrer index & 89.3 & 172.5 & 116.5848485 & 15.22634 \\
\hline Suprasternal height $(\mathrm{cm})$ & 127 & 160.5 & 144.6969697 & 6.939784 \\
\hline Waist circumference $(\mathrm{cm})$ & 63 & 93 & 73.96969697 & 6.465815 \\
\hline Wrist circumference $(\mathrm{cm})$ & 14 & 20 & 17.09848485 & 1.18393 \\
\hline Lower leg circumference $(\mathrm{cm})$ & 20 & 27.5 & 23.28030303 & 1.607982 \\
\hline Hand dynamometer bench $(\mathrm{left})(\mathrm{kg})$ & 18.6 & 55.5 & 35.14545455 & 8.067278 \\
\hline Hand dynamometer bench $(\mathrm{right})(\mathrm{kg})$ & 20 & 57.9 & 37.53181818 & 8.545339 \\
\hline
\end{tabular}

To group the boys' anthropometric data, their mean height and mean weight, and their standard deviations were calculated, and, based on them, five SD height-weight classes were formed: small, medium, big, leptomorphic and pycnomorphic (see Figure 1).

\begin{tabular}{|l|l|l|l|l|}
\hline \multirow{2}{*}{$\begin{array}{l}\text { Body build } \\
\text { classes }\end{array}$} & Weight classes \\
\cline { 3 - 4 } & Light & Medium & Heavy \\
\hline \multirow{2}{*}{$\begin{array}{l}\text { Height } \\
\text { classes }\end{array}$} & Short & 1. Small & \multicolumn{2}{|c|}{ 5. Pycnomorphic } \\
\cline { 2 - 4 } & Medium & 4. Leptomorphic & 2. Medium & \multicolumn{2}{|l}{ 3. Big } \\
\cline { 2 - 2 } & Tall & & \multicolumn{2}{|l}{} \\
\hline
\end{tabular}

Figure 1. Height-weight classification.

Table 2 shows the limits between classes. The table reveals that the height in the small class was between $161-174.95 \mathrm{~cm}$ and the weight between $42.60-$ $60.01 \mathrm{~kg}$. The height in the medium class was $174.96-181.93 \mathrm{~cm}$ and weight $60.02-72 \mathrm{~kg}$. The height in the big class was $181.94-195.5 \mathrm{~cm}$ and weight $72.01-102.30 \mathrm{~kg}$. The height of pycnomorphs (big weight, small height) ranged from $161.00-181.93 \mathrm{~cm}$ and weight from $60.02-102.30 \mathrm{~kg}$. Leptomorphs' (small height, big weight) height was $174.96-195.50 \mathrm{~cm}$ and weight $42.60-72$ $\mathrm{kg}$ (see Table 2). 


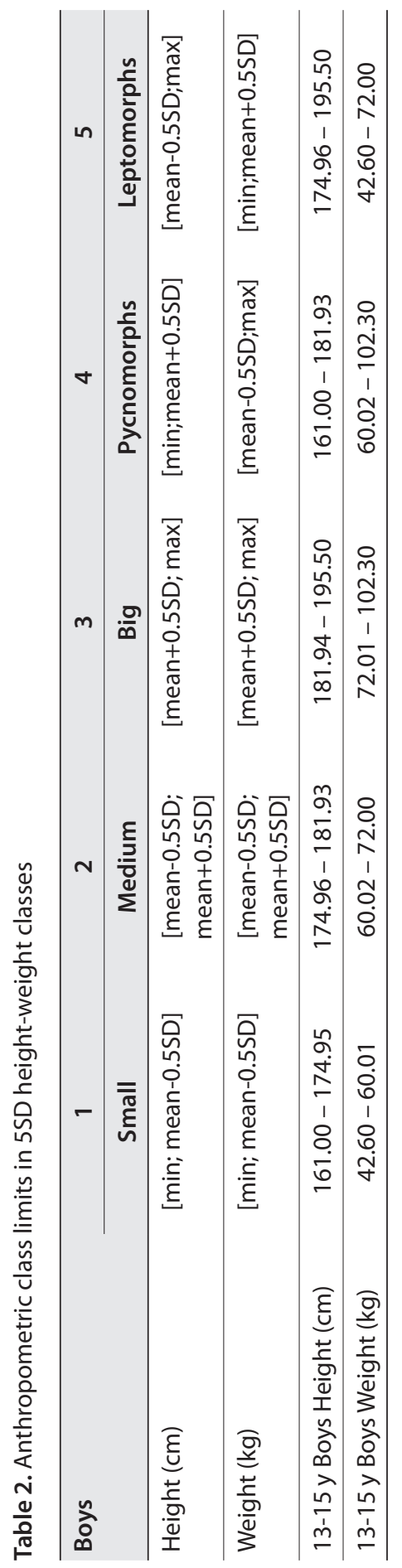




\section{Proficiency of attack}

Table 3 shows all boys' proficiency of attack during the whole tournament. The mean number of successful spikes per player during the whole tournament was 16.35 (SD 20.31). As maximum, one boy could perform 108 successful spikes during the whole tournament. The mean number of successful spikes per game was 2.41 (SD 2.87), the maximum mean of successful spikes was 15.42 per player. The mean number of spikes that remained in play was 15.62 (SD 16.06), the maximum number of spikes that remained in play by one boy was 57 . The mean number of spikes hit into the block was 5.40 (SD 5.72), the maximum number of spikes hit into the block during the tournament was 23 . The mean number of attack errors for the tournament was 8 (SD 8.16), the maximum number of attack errors by one player was 31 and the minimum 0 . The mean number of attack errors per game was 1.18 (SD 1.16), the maximum mean of number of attack errors in one game was 4.42 and minimum 0 per player. The mean number of spikes for the whole tournament was 39.98 (SD 41.70). The mean number of spikes per game was 5.91 (SD 5.87). Concerning the proficiency of attack, index of efficiency of attack and proficiency index, the sample studied consisted only of these boys who performed more than 5 spikes during the whole tournament (55 subjects). The mean proficiency of attack was 0.17 (SD 0.20), maximum 0.6 and minimum -0.3. The mean efficiency of attack was 0.37 (SD 0.14), maximum 0.7 and minimum 0.08 . The mean proficiency index was 0.58 (SD 0.10), maximum 0.8 and minimum 0.35 .

Tabel 3. Proficiency of attack during the whole tournament for all boys

\begin{tabular}{lccccc}
\hline Attack performance & $\begin{array}{c}\text { Number } \\
\text { of players }\end{array}$ & Mean & $\begin{array}{c}\text { Mini- } \\
\text { mum }\end{array}$ & $\begin{array}{c}\text { Maxi- } \\
\text { mum }\end{array}$ & $\begin{array}{c}\text { Standard } \\
\text { deviation }\end{array}$ \\
\hline Successful attacks (A1) & 66 & 16.35 & 0 & 108.00 & 20.31 \\
\hline Successful attacks - average per game & 66 & 2.41 & 0 & 15.42 & 2.87 \\
\hline Attacks remain in play (A2) & 66 & 15.62 & 0 & 57.00 & 16.06 \\
\hline Attack errors - block (A3) & 66 & 5.40 & 0 & 23.00 & 5.72 \\
\hline Attack errors - out (A4) & 66 & 2.59 & 0 & 12.00 & 2.86 \\
\hline Attack errors - total (A3+A4) & 66 & 8.00 & 0 & 31.00 & 8.16 \\
\hline Attack errors - average per game & 66 & 1.18 & 0 & 4.42 & 1.16 \\
\hline Attacks - total & 66 & 39.98 & 0 & 165.00 & 41.70 \\
\hline Attacks - average per game & 66 & 5.91 & 0 & 23.57 & 5.87 \\
\hline Proficiency of attack & 55 & 0.17 & -0.3 & 0.60 & 0.20 \\
\hline Efficiency of attack & 55 & 0.37 & 0.08 & 0.70 & 0.14 \\
\hline Index of proficiency at attack & 55 & 0.58 & 0.35 & 0.80 & 0.10 \\
\hline
\end{tabular}




\section{Boys' proficiency of attack depending on their body build}

The boys were placed in five anthropometric classes according to their individual heights and weights. The class of small boys included 13 boys, medium 12, big 10; there were also 14 pycnomorphs and 13 leptomorphs. Some boys did not play in the front line, and therefore, they have not been included in this context. Each boy's the parameters characterising attack activities were placed into body build classes to start the comparison of spike proficiency depending on body build (Table 4).

The mean total number of spikes in the small class was 34.69 (SD 39.66), in the medium class 33.75 (SD 31.81), in the big class 49.8 (SD 52.32), in pycnomorphs 28.5 (SD 40.62) and in leptomorphs 69.30 (SD 38.20). Statistically significant differences appeared between leptomorphs and the small class, leptomorphs and the medium class, and between leptomorphs and pycnomorphs $(\mathrm{p}<0.05)$. Thus, the greatest load at attack was carried by leptomorphs and players of the big class. The mean number of spikes per game was 5.07 (SD 5.60) in the small class, 5.37 (SD 4.21) in the medium class, 7.28 (SD 7.41) in the big class, 4.17 (SD 5.74) in pycnomorphs and 10.00 (SD 5.42) in leptomorphs.

In the number of successful spikes, there was statistically significant difference between the medium class and leptomorphs $(\mathrm{p}<0.05)$; the mean number of successful spikes in the medium class was 13.16 (SD 10.52) and in leptomorphs 27.15 (SD 18.23). Pycnomorphs and leptomorphs also differed statistically significantly $(\mathrm{p}<0.05)$ by the mean number of successful spikes -10.50 (SD 17.93) and 27.15 (SD 18.23) respectively. The other classes did not differ statistically significantly by the number successful spikes. The mean result of the big class in performing successful spikes was 24.9 (SD 32.81) and of the small class 13.61 (SD 18.70). The greatest number of points at attack was scored by leptomorphs, followed by players of the big class.

The mean number of successful spikes per game was 1.96 (SD 2.66) in the small class and 3.62 (SD 4.65) in the big class. Again, there was a statistically significant difference between the medium class and leptomorphs $(\mathrm{p}<0.05)-$ 2.08 (SD 1.34) in the medium class and 3.92 (SD 2.60) in leptomorphs. Pycnomorphs had 1.53 (SD 2.54) successful spikes per game on average, and they differed statistically significantly from leptomorphs $(\mathrm{p}<0.05)$. 


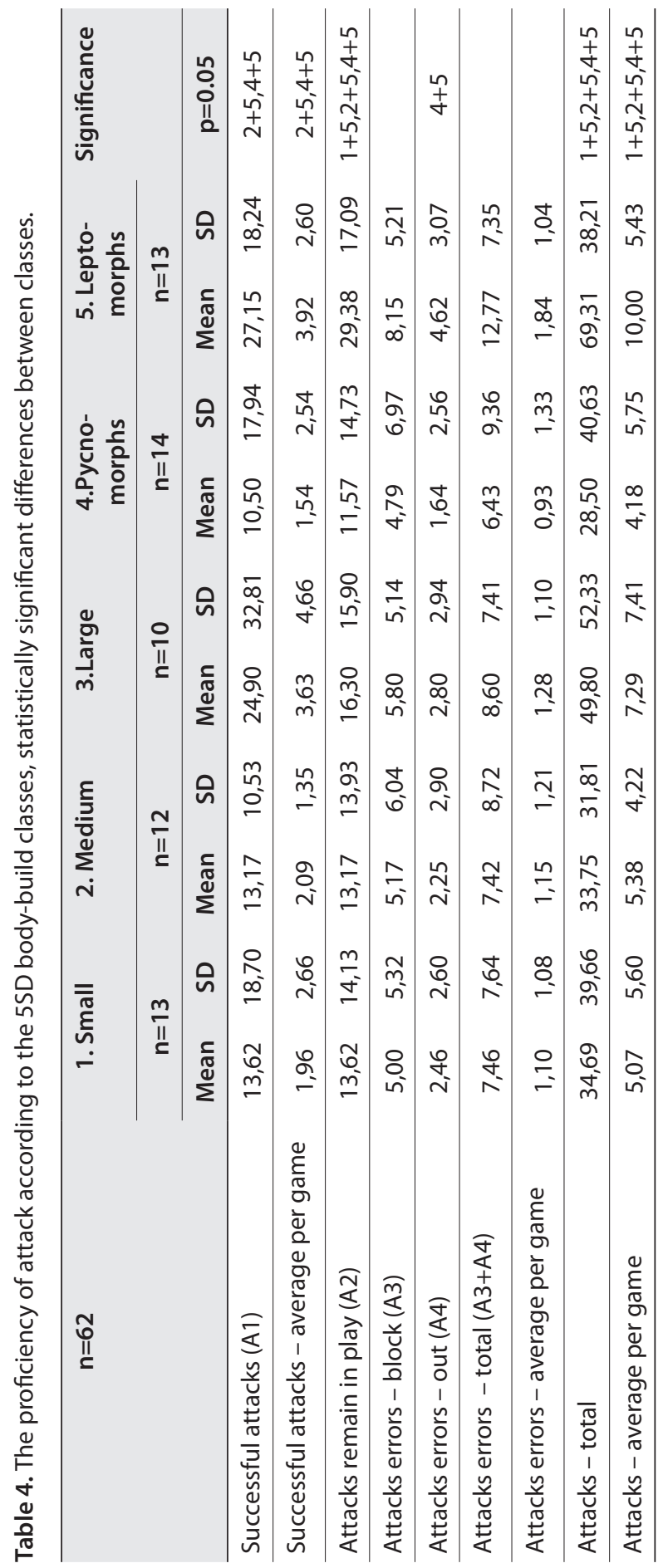


The mean total number of spikes in the small class was 13.61 (SD 14.12), in the medium class 13.16 (SD 13.92), in the big class 16.3 (SD 15.89), in pycnomorphs 14.73 (SD 40.62) and in leptomorphs 29.38 (SD 17.08). There were statistically significant differences between the small class and leptomorphs, between the medium class and leptomorphs, and between pycnomorphs and leptomorphs $(\mathrm{p}<0.05)$. As the children of the big class and leptomorphs were most active at attack, inevitably their number of spikes that remained in play was bigger than of the children of other classes who could perform fewer attacks.

The number of spikes into the block was 5 (SD 5.32) in the small class, 5.16 (SD 6.04) in the medium class, 5.8 (SD 5.13) in the big class, 4.78 (SD 40.62) in pycnomorphs and 8.15 (SD 5.20) in leptomorphs. There were no statistically significant differences between the classes.

The number of spikes going out of bounds was 2.46 (SD 2.60) in the small class, 2.25 (SD 2.89) in the medium class, 2.8 (SD 2.93) in the big class, 1.64 (SD 40.62) in pycnomorphs and 4.61 (SD 3.06) in leptomorphs. Statistically significant differences appeared between pycnomorphs and leptomorphs $(\mathrm{p}<0.05)$.

The mean number of attack errors was 7.46 (SD 7.64) in the small class, 7.41 (SD 8.72) in the medium class, 8.6 (SD 7.41) in the big class, 6.42 (SD 9.36) in pycnomorphs and 12.76 (SD 7.35) in leptomorphs. No statistically significant differences were revealed between any of the classes. There were no statistically significant difference in the mean number of attack errors per game either. The number of attack errors per game was 1.10 (SD 1.07) in the small class, 1.15 (SD 1.21) in the medium class, 1.28 (SD 1.10) in the big class, 0.93 (SD 40.62) in pycnomorphs and 1.84 (SD 1.04) in leptomorphs.

The conclusion could be drawn that leptomorphs and big boys were the most successful at attack. The total number of spikes performed by these two classes was much higher than in other classes, and, by the number of successful spikes, they were also better than the players of other body build classes. Our data revealed that the least successful class at spike were pycnomorphs. Their total number of spikes was the smallest, and the mean number of spikes was also smaller than in other classes. Surprisingly, the boys of the medium class were less proficient at attack than small boys. Statistically significant differences between the classes appeared in six indicators of attack: the number of successful spikes, the mean number of successful spikes per game, spikes remaining in game, spikes going out of bounds, and mean number of spikes per game. 


\section{Comparison of boys' proficiency of attack in sets won and lost}

The boys' activities at attack were now divided into two groups: attack activities by the boys in the sets lost $(n=61)$ and attack activities by the boys in the sets won $(n=65)$. The numbers are different as some boys did not play in any sets that were lost. In the sets won 10.07 successful spikes were performed (SD 14.78) and in the sets lost 7.22 (SD 9.54), but the difference was not statistically significant. The number of spikes remaining in play in the sets won was 7.35 (SD 8.11) and in the sets lost 9.32 (SD 11.74), but these indicators did not differ statistically significantly either. There was, however, a statistically significant difference $(\mathrm{p}<0.05)$ between the sets won and lost in spikes hit into the block. In the sets won, the mean number of spikes hit into the block was 2.2 (SD 3.02) and in the sets lost 3.59 (SD 4.08). In the sets won, the number of spikes going out of bounds was 1.09 (SD 1.58) and in the sets lost 1.68 (SD 2.05), and there was no statistically significant difference. The mean number of attack errors in the sets won was 3.29 (SD 4.37) and in the sets lost 5.27 (SD 5.83), and the difference between them was statistically significant $(\mathrm{p}<0.05)$. In the sets won, the mean number of attack errors was 0.48 (SD 0.58) and in sets lost 0.74 (SD 0.72), and the difference between them was also statistically significant $(\mathrm{p}<0.05)$. In proficiency and efficiency of attack and proficiency index, only the boys who had performed more than five attacks were taken into account. The proficiency of attack in the sets won was 0.30 (SD 0.19) and in the sets lost 0.04 (SD 0.20), and the difference was statistically significant, while in the sets lost the number of players who attacked more than five times was 39 , and in the sets won it was 45. The mean efficiency of attack in the sets won was 0.45 (SD 0.16) and in the sets lost 0.30 (SD 0.12), and there was also a statistically significant difference between them $(\mathrm{p}<0.05)$. The mean index of proficiency in the sets won was 0.65 (SD 0.09) and in the sets lost 0.52 (SD 0.10). In conclusion, it can be said that statistically significant differences did not occur in successful spikes but in attack errors. Therefore, in children of this age, smaller number of errors at attack is more essential for winning sets than the total number of successful spikes. It would be necessary to explain to children that they need not hit each ball to the ground, but it is essential, even in the case of poorer setting, to try to keep the ball in play, not to err (see Table 5). 
Table 5. Comparison of boy's proficiency at attack in sets won and lost

\begin{tabular}{|c|c|c|c|c|c|}
\hline \multirow[t]{2}{*}{ Boys } & \multicolumn{2}{|c|}{$\begin{array}{l}\text { Sets lost } \\
(n=61)\end{array}$} & \multicolumn{2}{|c|}{$\begin{array}{c}\text { Sets won } \\
n=65)\end{array}$} & \multirow{2}{*}{$\begin{array}{c}\begin{array}{c}\text { Statistical } \\
\text { differences }\end{array} \\
\text { p value }\end{array}$} \\
\hline & Mean & SD & Mean & SD & \\
\hline Successful attacks (A1) & 7.230 & 9.545 & 10.077 & 14.784 & 0.199022053 \\
\hline Successful attacks - average per game & 1.078 & 1.484 & 1.362 & 1.529 & 0.292340407 \\
\hline Attacks remain in play (A2) & 9.328 & 11.743 & 7.354 & 8.113 & 0.277704946 \\
\hline Attack errors - block (A3) & 3.590 & 4.084 & 2.200 & 3.022 & $0.032876472^{*}$ \\
\hline Attack errors - out (A4) & 1.689 & 2.054 & 1.092 & 1.588 & 0.072242076 \\
\hline Attack errors - total $(\mathrm{A} 3+\mathrm{A} 4)$ & 5.279 & 5.834 & 3.292 & 4.379 & $0.033669191 *$ \\
\hline Attack errors - average per game & 0.747 & 0.724 & 0.480 & 0.585 & $0.025424099^{*}$ \\
\hline Attacks - total & 21.836 & 25.799 & 20.723 & 25.748 & 0.808999311 \\
\hline Attacks - average per game & 3.047 & 3.237 & 2.999 & 2.896 & 0.930643659 \\
\hline Proficiency of attack ( $n=39 / 45)$ & 0.042 & 0.204 & 0.304 & 0.194 & $0.000000054^{*}$ \\
\hline Efficiency of attack ( $n=39 / 45)$ & 0.302 & 0.125 & 0.457 & 0.161 & $0.000004066^{*}$ \\
\hline Index of proficiency at attack ( $n=39 / 45)$ & 0.521 & 0.102 & 0.652 & 0.097 & $0.000000054^{*}$ \\
\hline
\end{tabular}

\section{DISCUSSION}

In their 2018 article, Helje Kaarma et al, have published normative indicators of Estonian school students' height and weight for each year of age from 7-18 [4]. In each age group studied by us (13, 14 and 15 years), the height of our volleyball boys was higher than the norms of Estonian school students. The weight in the sample studied by us was also higher than the weight norms of Estonian school students. In our opinion, it is good that the anthropometric characteristics of young men practising volleyball in Estonia are higher than the norms for Estonian school students. This shows that coaches search for players with appropriate body build who might become talented players in the Estonian men's national team.

Meelis Stamm found in his doctoral thesis that the most proficient performers of spikes were the boys of the big class and leptomorphs, followed by the players of the medium class, pycnomorphs and small boys [8]. In M. Stamm's study the boys of the small class attacked on average for 20.78 (SD 27.77) times for the tournament, the medium class 29.44 times (SD 15.09), the big class 55.73 times (SD 30.01), pycnomorphs 20.09 times (SD 20.32) and leptomorphs 48.33 times (SD 46.68). In our study, the mean number of spikes was higher in each class, which means that more spikes were performed during 
the tournament. As for successful spikes, in M. Stamm's study, the mean number of successful spikes in the small class was 6.11 (SD 10.13), in the medium class 11.22 (SD 7.87), in the big class 21.64 (SD 17.79) in pycnomorphs 6.00 (SD 6.78) and in leptomorphs 16.00 (SD 19.07), or, as said above the most successful performers of spikes were boys of the big class and leptomorphs. Our study also revealed that the greatest number of successful spikes were performed by leptomorphs and boys of the big class. Our study also showed that pycnomorphs had the poorest results in proficiency of attack.

According to our data, there were also differences between the winners and the losers in the proficiency index of attack but also in the efficiency index and number of errors at attack. Our study did not show, however, a statistically significant difference in successful spikes, which shows that if children of this age group want to win sets, they should err less often, not attempt to receive points from each ball. The results of this study form a very good theoretical substantiation for coaches when teaching children of this age group that each ball need not be hit to the ground, but the result greatly depends on the errors of one's own and the opponents' team. The coaches' role is to teach children that it is not important to score a point from each difficult ball at any rate, but it is essential not to err at attack. As our study showed, the statistically significant difference between winners and losers in this age group lies namely in attack errors, not in the number of successful spikes.

\section{REFERENCES}

1. Bandyopadhyay A. (2007). Anthropometry and body composition in soccer and volleyball players in West Bengal, India. J Physiol Anthropol, 26(4), 501-505.

2. Gualdi-Russo E., Zaccagni L. (2001). Somatotype, role and performance in elite volleyball players. J Sports Med Phys Fitness, 41(2), 256-262.

3. Kaarma H., Stamm R., Kasmel J., Koskel, S. (2005). Body build classification for ordinary schoolgirls (aged 7-18 years) and volleyball girls (aged 13-16 years). Anthropologischer Anzeiger, 63(1), 77-92.

4. Kaarma H., Veldre G., Saluste L., Lintsi M., Kasmel J., Tiit E.-M., Stamm R., Toomsalu M., Salm E., Kärik E., Arend A. (2018). Height and weight norms and somatotypic height-weight classification of Estonian schoolchildren aged 7-18 years. Papers on Anthropology, XXVII/1, 17-24.

5. Marques M., Tillaar R., Gabbett T., Reis V., Gonzales-Badillo J. (2009). Physical fitness qualities of professional volleyball players: Determination of positional differences. J Strength Cond Res, 23(4), 1106-1111. 
6. Nagendra K., Sundar R.U. (2013). Relationship of Selected Physical, Physiological, Psychological and Anthropometrical Variables with the Game Performance of College Men Volleyball Players. Doctoral Thesis, Bangalore University.

7. Raschka C. (2006). Sportanthropologie. Köln: Sportverlag Strauss (219-220).

8. Stamm M. (2015). Kehaehituse ja mänguedukuse terviklik seostatud hindamine võistlustel võrkpallipoistel vanuses 13-15 aastat. Dissertations on social sciences. Tallinn: Tallinn University Press, $130 \mathrm{pp}$.

9. Ugarkovic D. (2004). Biomedicinske osnove sportske medicine (Biomedical foundations of sports medicine). Novi Sad.

10. Volleyball Software, Stats v6.3. (2012). Estonian Volleyball Federation.

\section{Address for correspondence:}

Raini Stamm

Tallinn University

School of Natural Sciences and Health

Narva street 29, 10120 Tallinn, Estonia

E-mail: raini.stamm@tlu.ee 